\title{
FORMAÇÃO E ATUAÇÃO DO PSICÓLOGO PARA O TRATAMENTO EM SAUUDE E EM ORGANIZAÇÕES DE ATENDIMENTO À SAÚDE
}

\author{
TRAINING AND PROFESSIONAL PRACTICE OF PSYCHOLOGISTS IN HEALTH CARE AND IN \\ ORGANISATIONS THAT PROVIDE HEALTH CARE
}

Olga Mitsue Kubo ${ }^{1}$

Sílvio Paulo Botomé

\begin{abstract}
RESUMO
O exame da qualidade da preparação dos profissionais psicólogos para lidar com as variáveis relacionadas ao fenômeno saúde, permite identificar concepções fundamentais que interferem no tipo de atuação desse profissional. Conceituar saúde como fenômeno multideterminado, clarificar o objeto de estudo da Psicologia e de intervenção do psicólogo são requisitos que alteram significativamente o "fazer" profissional caracterizado, em grande parte, pela atividade clínica, para uma atuação ampliada do ponto de vista dos objetivos, dos tipos de problemas com que lida, dos procedimentos, do tipo de clientela e dos níveis de atuação. Conhecer as variáveis que viabilizam atuações profissionais mais eficazes e ensinar formas de realizar intervenções desse tipo é um desafio importante e urgente para os que investigam a Psicologia como área de conhecimento e para os que capacitam profissionais a intervir nos problemas sociais.
\end{abstract}

Palavras-chave: formação do psicólogo, trabalho em saúde, trabalho em organizações de saúde, ensino de Psicologia.

\begin{abstract}
An examination of the quality of the preparation of psychologists to cope with the variables relating to the health phenomenon enables the identification of fundamental concepts that interfere in the way the psychologist carries out his or her work. To conceptualise health as a multi-determinate phenomenon, to clarify the object of the study of Psychology and of intervention by the psychologist are requirements that significantly alter his or her professional modus operandi characterised, in the majority of cases, through clinical activity, towards a broader scope of work in terms of objectives, the types of problems to be dealt with, procedures, the type of patients and services provided. To understand the variables that enable psychologists to work more effectively and teach ways of undertaking interventions of this nature is an important and urgent challenge for those that investigate Psychology as an area of knowledge and for those that train professionals to intervene in social problems.
\end{abstract}

Key words: professional training of psychologists, health care, work in health care organisations, teaching of Psychology.

"Em que um físico nuclear pode contribuir para o marketing de uma empresa?" assim o autor de uma obra considerada revolucionária no meio da administração de empresas,

\footnotetext{
${ }^{1}$ Departamento de Psicologia da Universidade Federal de Santa Catarina. Caixa Postal 476 - 88010-970 - Florianópolis, SC - email: ok@cfh.ufsc.br.

${ }^{2}$ Departamento de Psicologia da Universidade Federal de Santa Catarina. Caixa Postal 476 - 88010-970 - Florianópolis, SC.
} 
inicia um exame minucioso das relações entre o mundo da ciência e dos negócios (Nóbrega, 1996, 1998). A tendência configurada no final do século XX e início do XXI, ainda que incipiente, parece ser de busca de um tipo de administrador diferente daquele até então requerido pelas empresas. Um profissional capaz de exercitar um tipo de criatividade diferente: um cientista. De acordo com Nóbrega, talvez demore para que um cientista chegue ao comando mais alto de uma grande empresa, mas ele tem qualidades que podem fazer que as idéias existentes sobre empresa, mercado e administração mudem e façam empresas obterem sucesso. Muitos estudiosos e pensadores estarão delineando nos primeiros anos do século $\mathrm{XXI}$, as características da sociedade pós-moderna, com o advento da globalização, com as rápidas mudanças que ocorrem nos contextos nacional e internacional. Formar um profissional cada vez mais habilitado a se comportar eficaz e eficientemente nesse novo contexto, tal qual os "novos executivos" requeridos na área empresarial identificados por Nóbrega (1998), é um desafio cada vez mais urgente a enfrentar. O profissional em Psicologia, como outros, estará preparado para enfrentar as exigências que as relações entre as instâncias sociais, políticas e econômicas da sociedade do terceiro milênio determinam?

A preparação de profissionais de nível superior é uma tarefa complexa que exige constantes estudos sobre a profissão, constantes avaliações dos vários aspectos que compõem as diferentes práticas do profissional e constantes correções de rumo do "fazer" profissional. Visualizar o "estado da arte" da Psicologia desde a década de 1960, quando ocorreu a regulamentação da profissão do psicólogo no Brasil, tem permitido obter informações acerca da qualidade da formação dos profissionais de Psicologia de um modo geral. Uma das maneiras de avaliar o trabalho do psicólogo tem sido por meio do exame do tipo de produção de conhecimento na área, dos avanços que são feitos em função dessa produção, das decorrências teóricas e práticas dessa produção para a Psicologia como área e como profissão e para o ensino de Psicologia no País.

O trabalho promovido pelo Conselho Federal de Psicologia e publicado em 1994 sob o título de "Psicólogo brasileiro: práticas emergentes e desafios para a formação", um aprofundamento do trabalho que diversos psicólogos realizaram e publicaram em 1992 ("Psicólogo brasileiro: construção de novos espaços") forneceu, entre outros aspectos, um conjunto de informações acerca da atuação profissional de psicólogos nos diferentes campos de atuação e permitiu identificar movimentos inovadores nas práticas consolidadas que, por sua vez, podem servir como subsídio para diretrizes e reformulações curriculares. Nesse contexto, Bastos e Achcar (1994) realizaram uma análise criteriosa a partir das informações obtidas e comentam que o modelo hegemônico que caracterizou a atuação do psicólogo no Brasil está sofrendo mudanças. As pesquisas realizadas em anos anteriores pelo Conselho Federal de Psicologia e por outros autores (CFP, 1988; Bastos, 1990, citado por Bastos e Achcar, 1994) permitiram identificar algumas características gerais do trabalho desenvolvido pelos psicólogos até o final da década de 1980. Uma delas, delineada por um amplo predomínio das atividades clínicas, marcadas por atuação em consultórios particulares, é a psicoterapia como atividade principal, dirigida a uma clientela adulta e de classe média. Outra delas, constituída por um trabalho na área organizacional, ocorre em empresas privadas, com predomínio das atividades de recrutamento, seleção e treinamento de pessoal. $\mathrm{Na}$ área educacional, predominaram as atividades de psicodiagnóstico, orientação psicopedagógica e orientação a pais, em geral em escolas particulares. Já na área social, em muitos casos, as atividades desenvolvidas não se distinguiram da atividade clínica, embora a diversidade de locais de trabalho abrangida pelos psicólogos que atuaram nessa área tenha sido maior do que nas décadas anteriores.

Aparece, contudo, na atuação profissional, caracterizada por meio de análise das publicações e por meio de entrevistas com psicólogos de diferentes campos de atuação, um movimento de transformação em uma ou em muitas das dimensões que caracterizam o trabalho profissional, avaliado no período aproximadamente compreendido entre 1988 e 1994: "Embora não constituam alteração quantitativamente significativa no conjunto dos psicólogos, tais movimentos sinalizam tendências ou rumos que podem redefinir a profissão, especialmente a amplitude dos serviços prestados à sociedade." (Bastos e Achcar, 1994, p. 249). Fica enfatizada a necessidade de garantir, por meio da formação, que essas tendências se fortaleçam e que atuações profissionais qualitativamente melhores deixem de ser experiências isoladas e alheias aos objetivos de formação do psicólogo e, de fato, 
transformem-se em contribuição para a Psicologia como um empreendimento coletivo e social de interesse para todo o país.

Botomé (1988) examina a busca de perspectivas para a Psicologia e identifica como condição necessária a clarificação dos conceitos de área de conhecimento, mercado de trabalho e campo de atuação profissional. Há o risco de não superação de muitos problemas detectados na atividade profissional se, no planejamento da formação do psicólogo e no exame do exercício profissional, não forem feitas as distinções entre as concepções da Psicologia como área de conhecimento, como campo de atuação profissional e como mercado de trabalho.

É difundida a noção de que as possibilidades de exercício de uma profissão são definidas pelo mercado. Segundo Botomé (1988), isto precisa ser, no mínimo, melhor examinado. "Mercado profissional define-se pelas ofertas de emprego existentes ou "esperáveis". Campo de atuação profissional é definido pelas possibilidades de atuação profissional, independentemente de "ofertas de emprego". O que importa, neste caso, são as possibilidades de atuação (ou, mesmo, as necessidades de atuação) e não apenas os empregos oferecidos." (p. 281). Uma formação profissional planejada sem considerar a distinção entre as concepções de mercado de trabalho e campo de atuação, corre o risco de formar psicólogos cuja atuação provavelmente ficará mais restrita àquilo que o mercado oferece ou solicita, e menos capacitado a empreender sua vida profissional buscando novas possibilidades de atuação.

Psicologia como área de conhecimento é definida por ter como objetivo o estudo (o conhecimento) de um determinado tema, assunto, objeto, fenômeno ou problema do ponto vista psicológico. O desenvolvimento de um campo de atuação profissional necessita da contribuição do conhecimento produzido por diferentes áreas do saber e não só do conhecimento de uma área, no caso, da Psicologia. A aprendizagem para ser capaz de integrar dados de diferentes naturezas e conhecimentos de diferentes áreas precisa ser alvo das instâncias responsáveis pela formação de um profissional psicólogo. Em outras palavras, formar um profissional capaz de não só "dominar o conhecimento psicológico" mas de "retirar do conhecimento existente informações que permitam derivar alternativas de atuação profissional" (Botomé, 1988, p. 279) precisa constituir um dos principais objetivos na formação do profissional. A formação do psicólogo requer, para seu planejamento, que sejam consideradas as necessidades da população, as possibilidades de atuação do campo e o conhecimento disponível.

Diante do desafio delineado pela exigência de planejar uma formação que capacite o profissional a atuar maximizando os benefícios de sua intervenção, as instâncias e segmentos envolvidos na formação do psicólogo precisam estar preparados para responder a questões, cujas respostas impulsionam na direção desejada: qual é a verdadeira extensão desse desafio? Qual o verdadeiro significado de tal empreendimento? Por onde começar? Focalizando um dos mais tradicionais campos de atuação do psicólogo, a clínica, é possível delinear os principais aspectos envolvidos no desafio de formar profissionais cada mais competentes e capazes de modificar significativamente a sociedade na qual se realizará a atuação desse profissional. Desde o final da década de 1960, quando foi realizado o estudo de Mello (1975), vários outros trabalhos demonstraram e discutiram o modelo que caracterizou fortemente a atuação clínica até final da década de 1980 (Carvalho, 1982; Bastos, 1988; CFP, 1992). Nos anos da década de 1990, no entanto, tornou-se perceptível um movimento de mudança dessa atuação centrada fundamentalmente no atendimento individual, para uma ampliação dos serviços prestados. É possível notar uma evolução dessa atuação caracterizando, com mais coerência e pertinência, uma intervenção em saúde. A despeito das controvérsias que podem e poderão surgir acerca dos critérios eleitos para demarcar as múltiplas atuações do psicólogo, (além dos tradicionais campos - clínica, escolar, organizacional - e de outros mais recentes como hospitalar, jurídico, da reabilitação, comunitária, do esporte, do trânsito), "atuação em saúde" significa uma atuação ampliada em relação àquela caracterizada até a década de 1980, do ponto de vista dos objetivos específicos do trabalho, dos tipos de problemas com que lida, dos alvos de intervenção, dos procedimentos utilizados, do tipo de clientela atendida etc., em cujo contexto se insere a atuação clínica, como uma das possibilidades da prática profissional do psicólogo da saúde. Quais serão as dimensões envolvidas na prática profissional no âmbito da saúde relevantes para o processo de formação do psicólogo? 


\section{ATUAÇÃO DO PSICÓLOGO NO CAMPO DA SAÚDE}

\section{E DA SAÚDE MENTAL}

Spink (1992), ao examinar o papel da Psicologia no campo da saúde, comenta: "A Psicologia chega tarde neste cenário e chega 'miúda', tateando, buscando ainda definir seu campo de atuação, sua contribuição teórica efetiva e as formas de incorporação do biológico e do social ao fato psicológico, procurando abandonar os enfoques centrados em um indivíduo abstrato e a-histórico tão freqüentes na Psicologia Clínica tradicional” (p. 12). Os esforços empreendidos pelo conjunto gradualmente maior de psicólogos envolvidos nessa área nos últimos anos da década de 1980 e no início da década de 1990, no entanto, estão produzindo rápidas transformações do "fazer" profissional, ainda em escalas limitadas. As mudanças ocorreram basicamente em duas dimensões: diversificação da atuação clínica, superando o sentido restrito do conceito e, uma segunda, que compreende a concepção sobre saúde mental, com reflexos nas atividades exercidas pelos psicólogos em hospitais e ambulatórios de saúde mental, com superação do enfoque psiquiátrico de internação e medicação do paciente (Spink, 1992, p. 12).

De acordo com Spink (1992) "a grande virada, no que diz respeito à inserção dos psicólogos nos serviços de saúde em São Paulo, ocorreu recentemente, a partir de 1982, com a adoção de uma política explícita, por parte da Secretaria da Saúde, de desospitalização e de extensão dos serviços de saúde mental à rede básica." (p. 13). Os aspectos essenciais dessa política para todo o território brasileiro, traduzida em dois projetos que traçaram as diretrizes de uma futura política de saúde mental comunitária, à semelhança dos modelos adotados por outros países, foram: a desospitalização ou redução progressiva do número de leitos em hospitais psiquiátricos, além da proibição de construção de novos hospitais psiquiátricos, a criação de serviços comunitários de assistência psiquiátrica alternativa à internação, tais como hospital-dia, hospital-noite, lares protegidos, oficinas de trabalho protegidas, unidades psiquiátricas em hospitais gerais, a implementação de programas de recuperação da população internada, trabalho em equipes multidisciplinares e a formação contínua dos profissionais de saúde mental pelas universidades e incentivo à atividade de pesquisa (Ministério da Saúde, 1987, citado por Bandeira, 1992). Essa política, surgida pela pressão do movimento que incorpora a crítica radical de "uma sociedade sem manicômios", levaria à criação de equipes de saúde mental integradas pelo menos por um psiquiatra, um assistente social e um psicólogo, constituindo uma rede de serviços teoricamente integrados com atuação nos níveis primário, secundário e terciário (Spink, 1991, p. 13).

O esforço da sociedade para superação do manicômio, no entanto, a despeito das experiências que podem ser consideradas bem sucedidas nesse contexto (Lo Bianco e col., 1994, p. 31-32), não isenta de uma análise crítica o papel que o psicólogo precisaria desempenhar na execução e consolidação de um projeto de saúde mental comunitária. Bandeira (1992) identifica várias atribuições do psicólogo, entre elas, a preparação do doente mental para sua reinserção social e sua manutenção na comunidade, a orientação da família dos pacientes, a preparação e orientação profissional do doente mental, a realização de pesquisas e avaliação de programas, a participação na formação dos demais trabalhadores de saúde mental e a produção de informação à sociedade sobre aspectos relacionados à saúde mental. A todas essas atribuições específicas do psicólogo soma-se ainda uma maior, que permeia a prática de todos os agentes envolvidos no projeto de saúde mental comprometido com o movimento antimanicomial: a de criar um "conjunto amplo de medidas que interfiram nas condições de vida do paciente e permitam criar alianças e vínculos forte com a comunidade" (Lo Bianco e col. , 1994, p. 32). Segundo Bandeira (1992), a implementação desse tipo de projeto em outros países tem apresentado dificuldades e limitações, algumas delas claramente decorrentes da formação deficitária do profissional, outras decorrentes das deficiências do sistema de saúde vigente. Estarão os psicólogos preparados para exercerem essas funções, superando as dificuldades advindas de um empreendimento dessa natureza?

Ao considerar a tendência geral do trabalho do psicólogo na "saúde mental", é possível dizer que algumas dificuldades estão sendo superadas e que o esforço do conjunto de profissionais dá possibilidade de tornar essa tendência perceptível (Arcaro e Mejias, 1990, Lo Bianco e col., 1994, Bastos e Achcar, 1994). É sabido, no entanto, que muitas dessas dificuldades ainda são de difícil superação, mesmo para profissionais experientes nesse campo de atuação. Ademais, há evidências do desconhecimento sobre aspectos importantes 
relacionados à "saúde mental" e dos principais fatores que podem afetar a manutenção do "doente mental" crônico na comunidade, por grande parte dos agentes responsáveis pela formação de futuros psicólogos em cursos de graduação em Psicologia no Brasil, como mostra Bandeira (1992) em seu estudo. A autora comenta ainda que uma das principais atividades necessárias para garantir o êxito de uma política de "saúde mental" é a atividade de pesquisa sobre a reinserção do "doente mental" e a divulgação desse conhecimento, juntamente com uma boa formação dos profissionais em "saúde mental" e a disponibilidade de informações de boa qualidade à sociedade. Os dados de Bandeira (1992) permitem concluir que a atividade de pesquisa na área de Saúde Mental é escassa e não tem recebido a devida importância e que as informações sobre a experiência de desinstitucionalização no Brasil também são escassas e de difícil acesso, tanto para pesquisadores quanto para outros tipos de profissionais envolvidos. As poucas oportunidades de serviços de estágio para alunos dos cursos de graduação em Psicologia, oferecidas pelos setores responsáveis, sugerem que há pouco conhecimento sobre aspectos relevantes do atendimento ao "doente mental" crônico e, ao mesmo tempo, deixa de "lançar mão" de uma das principais condições para o avanço do conhecimento na área.

Angerami (1997) identifica, como uma das primeiras dificuldades surgidas na atividade do psicólogo no contexto hospitalar, sua inserção no sistema institucional. Essa dificuldade, salienta o autor, advém do pouco preparo desse profissional pelas agências formadoras, dado, na passagem para o século XXI, os poucos cursos de graduação em Psicologia, que têm contemplado, em seus programas de formação, as experiências em contexto institucional. Silva (1992), ao examinar, especificamente, a formação do psicólogo para atuar no campo da saúde pública, destaca aspectos que permeiam a formação do psicólogo e que, de certa forma, são responsáveis pela manutenção de um único modelo de atuação (clínica) e, conseqüentemente, uma limitação das funções sociais da profissão. Continua a autora: "observamos que existe uma defasagem progressiva entre os conteúdos de formação universitária e as necessidades do setor de saúde (...) São várias as evidências que mostram que a universidade não está adequando a formação do graduando às reais necessidades da população" (p.35).

Nesse contexto, as instâncias responsáveis pela formação do psicólogo têm como desafio a avaliação dos rumos desse "fazer" profissional, para rapidamente realizar correções desses rumos, quando necessários. Os vários estudos realizados sobre atuação profissional, desde Mello (1975), têm permitido vislumbrar um panorama de amplas possibilidades de atuação, ou campo de trabalho, assim como a identificação das competências necessárias dos profissionais para ampliar esse "fazer", pela integração de conhecimentos de várias áreas e pela capacidade de "retirar do conhecimento existente informações que permitam derivar alternativas de atuação profissional" (Botomé, 1988, p. 279) e pela reaprendizagem, a partir de suas práticas, "reintegrando seus conhecimentos por meio de uma postura de constante investigação sobre elas" (Silva, 1992, p. 36). Há, apesar dos esforços e de concretizações de muitas experiências inovadoras nesse campo com bons resultados, indicadores de que é preciso ainda percorrer um "longo caminho" até que, de fato, um novo "fazer" se torne freqüente ou disseminado.

O que as agências formadoras precisam fazer para incorporar, como objetivos de formação, as competências importantes e desenvolver programas de formação mais consistentes e coerentes com os rumos exigidos pelas necessidades sociais existentes no início do século XXI? Os conceitos de saúde e de sua multideterminação parecem ser dois conceitos básicos, essenciais para capacitar o profissional para o trabalho com fenômenos relacionados à saúde, do ponto de vista dos processos de intervenção e de produção de conhecimento na área. Parece necessário realizar um minucioso exame de como o entrelaçamento entre esses conceitos e a Psicologia permite derivar competências socialmente relevantes e, transformando-as em objetivos de ensino, produzir um psicólogo melhor habilitado para realizar um trabalho com saúde.

\section{NOÇÃO DE SAÚDE COMO FENÔMENO}

\section{MULTIDETERMINADO}

O fenômeno saúde, considerado do ponto de vista físico e biológico de um organismo, pode ser examinado de diferentes maneiras. Uma das mais simples apresenta saúde e doença como dois fenômenos "dicotômicos" e invariavelmente separados. Essa maneira de conceber os fenômenos saúde e doença indica que eles são considerados como "pólos dicotômicos e 
opostos, na verdade, insuficientes para explicar grande parte dos fenômenos que ocorrem com as condições de saúde dos organismos" (Stédile, 1996, p. 23). Os indivíduos, no entanto, não são saudáveis ou doentes. Eles apresentam diferentes graus nas suas condições de saúde. Segundo Chaves (1980), "quando dizemos que uma pessoa está com ótima saúde, que está doente ou que está passando muito mal, estamos fazendo uma operação mental de relacionamento das características apresentadas pela pessoa quanto a um atributo, a sanidade, com as de diversos graus da escala de sanidade, procurando situá-la no ponto que nos parece mais justo" (p. 42). As variações que um dado organismo apresenta nas suas condições de saúde são constituídas por uma quantidade relativamente grande de fatores e de como esses fatores se combinam em um momento específico. Parece, dessa forma, mais apropriado dizer que saúde e doença são graus nas condições de saúde das pessoas.

No Brasil, segundo Stédile (1996), a VIII Conferência Nacional de Saúde (1988) ampliou significativamente o conceito de saúde vigente até então, incluindo não só as "condições de vida (alimentação, habitação, renda, ambiente, trabalho, transporte, emprego, lazer, liberdade, acesso à terra) mas também direitos ligados ao acesso universal e igualitário a ações e serviços de promoção, proteção e recuperação da saúde e exigências ligadas a uma política nacional de saúde" (p. 26). Com a ampliação do conceito de saúde, e a partir das contribuições de diferentes estudiosos que analisaram esse conceito, modificando-o e complementando-o (Chaves, 1980; Botomé e Santos, 1984; Rouquayrol, 1994; Backett e col. 1995 citado por Stédile, 1996), é possível dizer que a separação dos fenômenos saúde e doença é inadequada e que esses termos referem-se a diferentes graus que constituem as condições de saúde de um organismo. Considerar esses graus significa "olhar" para o fenômeno saúde e não apenas para um evento estático: uma condição de saúde de um organismo em um momento específico ou em uma condição determinada (Stédile, 1996, p. 36). O Quadro 1 ilustra esquematicamente alguns dos valores que pode ter a variável "condições de saúde de um organismo". A operação de qualificação envolve uma identificação das características de uma pessoa e um relacionamento com uma escala de sanidade em que, entre os extremos ("plena condições de saúde" e "morte"), podem existir múltiplos valores, isto é, as condições de saúde de uma pessoa podem ter qualquer valor em um continuum entre o máximo de saúde e o máximo de sua falta (doença).

Além da concepção sobre como entender saúde (melhor do que uma dicotomia), há um segundo aspecto igualmente importante que precisa ser examinado: ele diz respeito aos determinantes das condições de saúde de um organismo. As variações que uma pessoa pode apresentar nas suas condições de saúde dependem da combinação de uma quantidade relativamente grande de fatores de naturezas diversas. "As evidências disponíveis atualmente já permitem afirmar que examinar a ocorrência de eventuais enfermidades apenas por meio de sua determinação biológica, sem considerar a influência dos processos sociais sobre essa ocorrência, é considerar o fenômeno de maneira parcial e incompleta" (Rebelatto e Botomé, 1999, p. 187). A Epidemiologia Social, definida de maneira ampla, como a ciência básica da saúde coletiva, que estuda o processo saúde-doença, sua distribuição e seus determinantes em grupos humanos (Rouquayrol, 1994), tem evidenciado, a partir do século passado, a participação de múltiplos fatores como determinantes do fenômeno condições de saúde. San Martin (1981, citado por Rouquayrol, 1994) designa o conjunto formado pelo ambiente, população, economia e cultura, como sistema epidemiológico-social, um sistema amplo que abrange tanto os modos de produção e relações de produção, até a responsabilidade individual e coletiva e que constituem os componentes essenciais e determinantes do "processo saúdedoença" ou, em linguagem conceitualmente mais coerente, do fenômeno "condições de saúde". Dessa forma, fatores agrupados pelos termos gerais de "sociais", "ambientais" e "genéticos" são componentes a serem considerados quando o objetivo é a melhoria da qualidade de vida das coletividades humanas.

Quadro 1: Alguns dos valores que pode assumir a variável "condições de saúde de um organismo" (Reproduzido de Chaves, 1980). 
PLENAS CONDIÇÕES DE SAÚDE

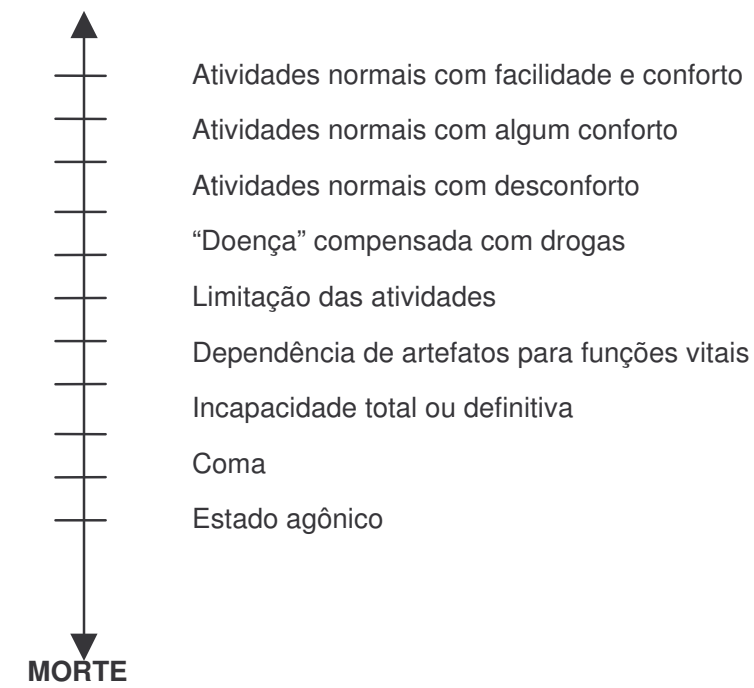

Considerar que condições de saúde dos indivíduos dependem de uma complexa rede de inter-relações entre fatores ou variáveis que compõem essas condições e as determinam, significa dizer que as relações de determinação são probabilísticas, isto é, dependendo do arranjo e configuração (estruturação) dos diferentes fatores, as condições de saúde tendem a melhorar, piorar, permanecer constantes e outras possíveis graduações no continuum das condições de saúde. Significa que não é possível determinar com precisão absoluta, mas apenas com aproximações probabilísticas, os estados ou as ocorrências dos eventos na natureza. Cada gradiente do continuum "saúde-doença" (das condições de saúde) é determinado de acordo com os arranjos dos valores das demais variáveis presentes em uma "rede" de relações. As combinações, a cada momento, entre os valores dessas variáveis, fazem que uma condição de saúde seja não um fenômeno estático e com limites definidos e estáveis, mas um fenômeno dinâmico, com múltiplas possibilidades de composição caracterizando, assim, um processo complexo e dinâmico (Stédile, 1996), para o qual o sistema conceitual disponível não parece corresponder suficiente e adequadamente.

Chaves (1980), ao analisar a importância e os impactos de ações profissionais sobre o processo gerador de alterações nas condições de saúde, comenta que a melhoria das condições de vida traz implícita a idéia da vida em um ambiente mais favorável. O saneamento ambiental é uma das pedras fundamentais da saúde pública e inclui, além das ações de saúde dirigidas principalmente para as condições ambientais (água, ar, alimentação, radiação, disposição de dejetos e saneamento geral), também ações sobre a sociedade. $O$ autor apresenta, como exemplo, o caso de várias doenças cujas origens podem ser atribuídas às tensões produzidas no indivíduo pelo ambiente social em que ele vive. Fatores como expectativas da família e do grupo no qual o indivíduo se insere, a competição por melhores posições na hierarquia das organizações em que trabalha, frustração pelo tipo de trabalho que desenvolve, número insatisfatório de horas de lazer, são identificados como sendo conseqüência do tipo de relações sociais, econômicas e culturais praticadas pelos indivíduos de determinadas sociedades. Desse ponto de vista, para uma atuação em saúde, de maneira mais ampla, é condição fundamental adotar uma concepção sistêmica de saúde, de modo que um planejamento de ações integradas possa ser feito. Segundo o autor, as ações de saúde são desenvolvidas por vários setores sociais Algumas delas estão plenamente caracterizadas como tendo o fim específico de garantir diretamente melhores condições de saúde. Outras, pela sua natureza, caracterizam-se como sendo de responsabilidades de outros setores da sociedade usualmente não considerados como pertencendo a esse campo, mas, nem por isso devem deixar de ser consideradas como ações de saúde, em um sentido mais amplo. Planejar integradamente um trabalho de saúde requer que esses diferentes setores responsáveis pelas ações de saúde considerem essas ações como tarefas de um sistema social único, o sistema de saúde, tendo como pressuposto de que saúde é um fenômeno multideterminado e que 
somente ações de múltiplos tipos e integradas poderão alterar qualitativamente o perfil de saúde dos indivíduos da sociedade como um todo (Chaves, 1980, p. 77).

A percepção da saúde como um fenômeno multideterminado aumenta as possibilidades de mudanças nos comportamentos dos profissionais que atuam nesse campo, tanto em relação ao tipo de intervenção feita quanto em relação ao tipo de conhecimento produzido sobre o fenômeno saúde do ponto de vista das múltiplas áreas do saber relacionadas a ele. Uma decorrência para o trabalho dos profissionais de saúde parece ser a facilitação do trabalho multiprofissional, pela clarificação das diferentes contribuições de cada profissional ao tratar das variáveis componentes do fenômeno saúde e dos seus determinantes, tanto no que se refere aos limites de cada campo de atuação, quanto a suas sobreposições. Situar o objeto de intervenção e de estudo da Psicologia em relação ao fenômeno saúde se torna assim não uma tarefa simples, mas, sem dúvida, uma tarefa mais claramente definida pela possibilidade de percepção da "rede" de interrelações entre as diferentes variáveis. É de supor que o âmbito de atuação da Psicologia não se limita às interferências sobre variáveis de natureza apenas psicológica, mas abrange todas as relações possíveis entre as variáveis psicológicas e as demais que se relacionam com o fenômeno "saúde".

Ao examinar o que acontece com alguém quando uma das variáveis do sistema se altera, fica difícil separar o que acontece nas categorias que correspondem às áreas de conhecimento. A intervenção em um campo de atuação usa "recortes" e critérios de categorização diferentes daqueles usados para separar as áreas de conhecimento. O mesmo raciocínio pode ser utilizado em relação aos problemas de pesquisa, ou aos "recortes" a serem feitos para eleição das relações a serem estudadas pela Psicologia, como área de conhecimento, nessa "rede" de relações, que envolve as variáveis de ordem psicológica e as condições de saúde. O desafio permanente para todos os profissionais de saúde e, em particular, para o psicólogo, é o de saber integrar os conhecimentos dessas diferentes áreas para sua atuação e transformá-los em condutas profissionais e saber retirar das situações de intervenção novas perguntas de pesquisa, que por sua vez, ao serem respondidas, possibilitarão produzir intervenções cada vez mais eficazes, do ponto de vista de recursos tecnológicos, dos processos comportamentais envolvidos, de procedimentos, de avaliação etc. Em qualquer caso, conhecimentos de uma área não correspondem aos conhecimentos necessários para realizar as intervenções próprias de um campo de atuação profissional.

\section{ÂMBITOS DE ATUAÇÃO PROFISSIONAL E POSSIBILIDADES DE CONTRIBUIÇÃO DA PSICOLOGIA PARA A SAÚDE}

A noção de saúde como fenômeno multideterminado, envolvendo variáveis de diferentes áreas do conhecimento, facilita "enxergar" com maior clareza o complexo sistema de relações do qual as variáveis psicológicas fazem parte. "Enxergar" possibilidades de intervenção profissional e de relações a pesquisar nesse universo requer, todavia, que pesquisadores e profissionais de Psicologia tenham também, com a mesma clareza, noção do objeto de estudo e de intervenção da Psicologia e das amplitudes possíveis que podem ter os seus limites e intersecções com outras áreas do conhecimento e com os variados campos de atuação profissional. Muitos exames foram feitos acerca do que constitui o objeto de estudo da Psicologia e de intervenção do psicólogo e, mesmo assim, as concepções sobre ele não estão livres de controvérsias. Todorov (1989) comenta que "definições de Psicologia têm variado no tempo e de acordo com as características de seus autores. Problemas surgidos no âmbito da Filosofia ou da Ciência refletem-se em várias dessas definições. Por exemplo, é muito conhecida a definição de Psicologia como estudo da mente (...) Alguns preferem referir-se a uma vida mental (...) Outros (...) afirmam ser a Psicologia o estudo do comportamento." (p. 347348). Qualquer que seja a definição escolhida, carecerá de outras definições para aclarar o que venha a ser "mente", "vida mental" ou "comportamento". A conclusão do autor é de que dificilmente qualquer definição adotada conseguirá agradar "gregos e troianos" ao mesmo tempo ou, sem metáforas, mais precisamente, "mentalistas" e "comportamentalistas". A tese defendida por Todorov (1989) é de que se poderá caracterizar a Psicologia de um ponto de vista e, "tentar, depois, mostrar como essa caracterização é compatível com os variados tipos de atividades do psicólogo..." (p. 348). Ou seja, demonstrar que o que é feito na área é compatível com a caracterização da Psicologia, tendo como referente algum dos pontos de vista possíveis.

De um desses pontos de vista da Psicologia (o da Análise do Comportamento), por exemplo, o trabalho com a Saúde não só se refere à patologia seja ela física, biológica, 
fisiológica ou psicológica, mas às variáveis que as determinam ou que delas decorrem em vários âmbitos de abrangência. Trabalhar com o planejamento ou com a administração de uma instituição (Botomé, 1981a e Melchiori, 1987, por exemplo) que lide com processos de saúde fisiológica, por exemplo, é um processo mais psicológico, administrativo, organizacional ou social do que fisiológico ou biológico. Planejar o sistema de saneamento ou de abastecimento de água de uma cidade ou administrá-lo, interfere diretamente sobre as condições de saúde, embora tal trabalho não seja, usualmente considerado da "área da saúde" (mesmo considerando o "tema saneamento" um assunto de saúde pública). De forma semelhante, lidar com as decorrências de uma epidemia sobre o trabalho, ou outros tipos de atividades, de uma comunidade também poderia - ou não? - ser considerado um trabalho em "Saúde". No âmbito da Psicologia, pelo menos do ponto de vista da Análise do Comportamento, o trabalho com a Saúde refere-se a qualquer tipo de comportamento que faça parte do sistema de variáveis, que afete ou seja afetado pelas alterações sociais, fisiológicas, químicas, biológicas, ambientais e outras que interferem com a qualidade das relações de um organismo com seu meio ou contexto de vida, a curto, médio ou longo prazos.

Coerentemente com essas considerações, a base para caracterização da Psicologia, do ponto de vista da Análise do Comportamento, segundo Todorov (1989), é considerar que o objeto de estudo da Psicologia são as interações dos organismos com seu ambiente. Botomé (1981b, 1998), ao considerar como objeto da Psicologia o comportamento humano, definido como a relação entre ação (classes de respostas) do organismo e o meio em que realiza essa ação, da mesma forma, caracteriza um determinado tipo de "interação" como o aspecto nuclear e essencial dessa definição. A noção de comportamento como uma relação entre a ação do organismo e aspectos do meio no qual a ação ocorre e que dela decorrem nem sempre foi assim. Segundo Botomé (1998, p. 18), se for observada a diferença entre o que Skinner, uma dos cientistas mais identificados com o conceito de comportamento e um dos que mais contribuiu para o avanço do conhecimento sobre esse tipo de fenômeno, considerava em 1938 e o que considerou em 1969, houve um longo percurso. Há uma evolução do conceito de comportamento desde a primeira vez em que ele foi formulado por Skinner em 1938, quando afirmava que o comportamento era uma parte da atividade total de um organismo e que era aquilo que um organismo fazia, até formulá-lo, em 1969, como dependente de complexas interrelações entre o estímulo antecedente, a resposta e o estímulo conseqüente (Skinner, 1969, p. 18). Além de Skinner, vários estudiosos contribuíram para o aprimoramento do conceito de comportamento, salientando a importância de distinguir, com clareza, os critérios usados para definir uma relação comportamental. Para construir um sistema conceitual que seja capaz de descrever, o mais fidedignamente possível, o que acontece com as pessoas quando estão em interação com o ambiente, é preciso usar definições acuradas dos principais conceitos sobre os quais "repousa" esse sistema. Assim definições de termos como resposta, classe de respostas, estímulo, estímulos antecedentes, estímulos conseqüentes, efeitos etc. precisam ser esclarecidas e elaboradas de forma muito mais clara e precisa para serem úteis (Botomé, 1981b).

Os estudos realizados na área da Análise do Comportamento permitiram a descoberta de uma variedade de dados que possibilitam entender e lidar com o comportamento como uma relação entre ação e meio, não mais como apenas aquilo que era a ação observável do organismo. As decorrências desse tipo de concepção são muito grandes e variadas a respeito de quase todos os fenômenos com que as pessoas lidam ou se defrontam. Uma das principais diz respeito à possibilidade de perceber que comportamento não é um fenômeno simples, de fácil identificação. Ao contrário, essa concepção de comportamento permite perceber o quão complexo e de difícil identificação é ele, dada a sutileza das relações que o compõem e o definem, e dado o caráter efêmero dos eventos que constituem tais relações. Nesse sentido, investigar por que as pessoas se comportam como se comportam parece constituir o objetivo maior da Psicologia.

Essa pergunta, todavia, teve sua resposta reiteradamente buscada por cientistas e estudiosos do comportamento "olhando" para "dentro de cada um" na busca de explicação para a determinação do comportamento e tendendo a atribuir as "causas" a processos internos reais ou fictícios - ("vontade", "motivação", "necessidade"). Uma direção de exame que parece ser mais promissora e que, segundo Skinner (1969), caracteriza a tarefa do analista de comportamento, é buscar descobrir todas as variáveis das quais o comportamento é função. Identificar, contudo, os fatores (variáveis) que determinam o comportamento humano não é uma tarefa simples, nem isenta de dificuldades. Ela requer esforços para elucidar conceitos e definições com rigor necessário para possibilitar estudos sobre a natureza das relações que mantém com os organismos e, muitas vezes, "esbarrando" nos limites impostos por uma 
linguagem geralmente insatisfatória para descrever novas e antigas maneiras de se referir aos comportamentos dos agentes envolvidos nos sistemas em estudo. A tarefa requer também, como condição fundamental, uma preparação para lidar com a concepção de que comportamento, assim como o fenômeno saúde, é multideterminado. Skinner (1969) no prefácio de sua obra "Contingências de reforço", ao discorrer sobre o método mais apropriado para estudar comportamento humano, apresenta algumas questões consideradas importantes para o de- senvolvimento da ciência do comportamento. Entre essas questões podem ser destacadas: "que aspectos do comportamento são significativos? De quais variáveis são função as mudanças nesses aspectos? De que forma as relações entre o comportamento e suas variáveis controladoras podem ser combinadas ao caracterizar um organismo como sistema?". O aspecto que parece ser importante para análise é que essas questões somente serão passíveis de respostas se uma percepção de comportamento como interação entre ação do organismo e aspectos do ambiente no qual a ação ocorre e de comportamento como fenômeno determinado por variáveis em interação, formando um sistema complexo, estiver suficientemente desenvolvida para balizar os comportamentos de pesquisadores e profissionais que trabalham no âmbito da Psicologia ou utilizam esse conhecimento para atuar em outros campos profissionais.

Quando é considerado o estudo do comportamento, historicamente, várias subáreas da Psicologia têm se caracterizado em função da natureza das relações enfatizadas (Psicologia social, organizacional, clínica, do desenvolvimento, aprendizagem etc.). O ambiente tem sido dividido, em geral, em dois níveis, externo e interno, e esses, por sua vez, compartimentalizados em físico e social, biológico e histórico, respectivamente. Ainda que seja sabido que essas distinções são apenas de ordem didática - e, portanto, artificiais - ou para facilitar o entendimento da fragmentação da Psicologia em diferentes subáreas (Todorov, 1989), elas são úteis para ajudar no entendimento das possibilidades de estudos e de atuação profissional do psicólogo e, em particular, do psicólogo que elege as relações entre saúde e seus determinantes ou suas decorrências como objeto de estudo ou de intervenção. Ora, se saúde é um fenômeno multideterminado, isto é, variáveis psicológicas são um conjunto dentre outros que o determinam ou que dele decorrem e se comportamento é o objeto de estudo da Psicologia, definido e estudado como interação entre organismo e ambiente e, ainda, se a distinção entre a Psicologia e outras áreas de saber não se baseia em fronteiras rígidas (ao contrário elas, muitas vezes, se sobrepõem, com reflexos diretos sobre o tipo e a maneira de intervir dos profissionais envolvidos), pode ser percebido que o universo de possibilidades de estudo e de intervenção do psicólogo em relação ao fenômeno saúde é muito amplo. Principalmente se ainda for acrescentado que o mesmo raciocínio sobre os múltiplos determinantes ampliar os limites do campo de atuação e da área de conhecimento que pode chamar-se Saúde também pode ser feito para múltiplas decorrências de alterações no organismo usualmente consideradas como "alterações na saúde".

Alguns dos trabalhos que ilustram a análise apresentada por Lo Bianco e col. (1994) acerca da trajetória da Psicologia Clínica no Brasil na década de 1990, descrevem tipos de trabalhos desenvolvidos no campo da saúde em uma perspectiva bastante diferenciada daquela que predominou na década de 1980. Essas experiências, além de serem uma indicação de uma melhor direção do trabalho do psicólogo clínico, principalmente do ponto de vista social, constituíram fonte para identificação de competências que os profissionais precisam apresentar ao lidar com o fenômeno saúde. Os estudos de Melchiori (1987) e Botomé (1981a) são ilustrativos das possibilidades de atuação de psicólogos ao lidar com variáveis relacionadas à saúde, do ponto de vista de serem trabalhos pouco usuais quando comparados ao perfil dos trabalhos desenvolvidos no período no qual foram realizados.

Melchiori (1987) realizou um estudo, envolvendo uma amostra das famílias de um município, e todos os profissionais liberais que atendiam pessoas com "deficiência mental" desse mesmo município, cujo objetivo foi identificar aspectos da realidade social relevantes para orientar comportamentos de um profissional de Educação Especial, em relação às condutas de vida da população de "deficientes mentais", aos tipos de atendimento que essa população precisava receber e às características das condições de vida da população de risco. Os dados desse estudo permitiram derivar várias classes de ações indicadoras de necessidade de atuações específicas por parte de agências sociais responsáveis pela oferta de serviços de saúde. Em outras palavras, permitiam explicitar os pontos de partida, pelos quais uma agência prestadora de serviços de saúde deveria orientar-se ao planejar e implantar serviços de saúde. Uma agência assim planejada teria condições de oferecer serviços nos quais os profissionais se comportariam em função das necessidades da população e seriam capazes de exercer 
controle sobre as variáveis que determinam a incidência da "deficiência mental" nessa população ao longo de um período de tempo definido.

Botomé (1981a), por meio de um estudo desenvolvido com os postos de saúde no Município de São Paulo, demonstrou que um planejamento feito a partir da percepção de que seriam as agências prestadoras do serviço de saúde responsáveis pelo pronto atendimento à população que dele necessita, com eficácia, deixando de "culpar" o usuário pelos freqüentes fracassos de programas de saúde colocados em vigência até então, resultou em mudanças substantivas tanto na maneira de atendimento nos postos de saúde como nos comportamentos dos usuários desses postos. O planejamento foi conduzido explicitando os comportamentos necessários que os diferentes agentes dos postos de saúde precisariam apresentar para maximizar a qualidade dos atendimentos oferecidos caracterizados a partir de uma identificação precisa das necessidades dos usuários dos serviços. Dessa forma, a análise de comportamentos envolvidos no sistema de atendimentos possibilitou o planejamento desses diferentes serviços de maneira integrada e mais eficaz, num raro exemplo para a época, de construção de um sistema sensível às demandas do meio e que permitiu produzir elevação nas condições de saúde das pessoas que dele necessitavam e que o utilizaram nas novas condições de funcionamento.

Ferreira e col. (1984), quando examinam as relações entre deficiência física e inserção social construídas pela formação de pessoal no campo da saúde, também ilustram um trabalho de Psicologia no campo da Saúde que sai do que, no tempo em que foi feito, não era usualmente considerado "da saúde", talvez nem "da Psicologia". Vinte anos depois, a amplitude dos objetos de estudo e de intervenção da Saúde e da Psicologia tem muito mais dimensões, amplitude e complexidade do que era usualmente considerada nos trabalhos das décadas anteriores.

Os trabalhos de Botomé (1981a), Ferreira e col. (1984) e Melchiori (1987) constituem três exemplos que ilustram como a integração de duas ou mais áreas de conhecimento possibilitam uma atuação de melhor qualidade (análise do comportamento, desenvolvimento humano, planejamento, organizações, administração, educação especial, formação em nível superior) e já se referiam a critérios e procedimentos que, na década de 1990, passariam a ser considerados como "planejamento estratégico situacional" (Huertas, 1996), também um importante tipo de conhecimento que integra comportamento e realidade social. Zannon (1991), em um artigo de revisão sobre questões teóricas relacionadas às práticas profissionais, particularmente, à atuação do psicólogo ao lidar com crianças hospitalizadas, examina a importância de revisões dos conceitos considerados cruciais sobre os quais "repousa" uma dada prática profissional. Ressaltando a importância de esforços para a proteção à vida da criança, a autora examina a necessidade de efetuar uma revisão teórica-conceitual da relação entre ambiente e comportamento, como subsídio para orientar a prática profissional condizente com uma direção para lidar com pessoas, integrando as perspectivas biológicas, psicológicas e sócio-culturais. Um trabalho assim conduzido, muito provavelmente, culmina em práticas que interferem sobre os processos comportamentais da criança, seus familiares e dos profissionais que a atendem, melhorando as condições da criança hospitalizada. Salientando desse estudo o aspecto que interessa para análise, há um exemplo de preocupação não só com a qualidade do conhecimento que embasa o "fazer" profissional, mas também com a necessidade de integrar conhecimentos (de análise do comportamento, de desenvolvimento, de biologia, de ciências sociais) para uma melhor atuação do psicólogo em saúde.

Considerando as múltiplas possibilidades de trabalho envolvendo psicologia e saúde, e comparando com o que, de fato, está sendo feito, apesar das várias experiências bem sucedidas que possibilitam novas formas de atuação para os psicólogos no campo da saúde, é possível perceber que ainda há muito por fazer. A contribuição que a Psicologia poderia dar ao planejamento, execução, acompanhamento e avaliação aos programas governamentais de saúde como, por exemplo, aos projetos de âmbito nacional para assistência e controle do câncer, das doenças sexualmente transmissíveis e da AIDS, pode ser considerada como crucial para o sucesso desses programas. Dado que, em projetos dessa natureza, a mudança de comportamento da população é fator fundamental para controle e prevenção desses tipos de doenças, fica evidenciado o valor da contribuição do conhecimento psicológico em integração com os demais conhecimentos advindos das diferentes áreas do saber necessárias para intervir em situações como essas. Quais as providências a tomar para acelerar o avanço da Psicologia, em interseção com a Saúde, na direção de uma rápida socialização dos benefícios decorrentes de uma área de conhecimento em franca expansão? 


\section{POSSIBILIDADES NO ENSINO DA PSICOLOGIA PSICÓLOGOS PARA O TRABALHO EM SAÚDE}

Ao examinar a expressão "Psicologia da Saúde", para caracterizar tipos de estudo ou de intervenção de psicólogos em relação a fenômenos que podem ser reunidos sob o nome "saúde", parece ser um nome amplo e talvez inadequado. A inadequação se deve ao fato de que a expressão "da saúde" delimita previamente fenômenos e relações entre fenômenos que são conhecidos e identificados tradicionalmente como pertencendo ao campo ou área da saúde, ou então pelas características dos recursos tecnológicos e de procedimentos e técnicas conhecidos e identificados como sendo do campo da saúde. Um exame comparativo com a expressão "Psicologia em Saúde", uma denominação que parece ser mais apropriada, permite considerar como objeto de investigação e de intervenção uma gama muito maior de fenômenos e de suas relações, dadas as múltiplas dimensões dos fenômenos e a natureza dos sistemas nos quais eles estão inseridos. Pode significar as diferentes formas e tipos de estudo que podem ser feitos das relações entre as variáveis psicológicas e as que constituem o fenômeno "saúde". Relações que podem ser de determinação (influência) dos diferentes graus das variáveis componentes do comportamento (ou dos fenômenos psicológicos) sobre as condições biológicas dos indivíduos (ou sobre outras variáveis que determinam essas condições). Ou, relações que podem, ao contrário, ser de determinação das condições biológicas (ou das variáveis que as constituem ou determinam) sobre as variáveis que constituem ou determinam as características do comportamento (ou das variáveis psicológicas).

Os estudos podem variar desde os mais básicos, de investigação de variáveis químicas, ambientais etc. sobre as interações entre organismo (biológico, fisiológico) e comportamento em simulações de laboratório (ou, sobre aspectos ou decorrências dele), até os mais "aplicados" ou "de campo" (no ambiente natural), onde podem ser investigadas relações desse tipo (por exemplo, populações ou pessoas submetidas a situações de sofrimento, de ameaça, de incerteza, de privações etc. e o que acontece com suas condições psicológicas e biológicas. Os estudos podem também, em todos os tipos e níveis, ser feitos na direção de influência inversa: condições psicológicas (sejam quais forem e em que grau) afetando condições de saúde de organismos ou coletividades de organismos.

Além dos estudos caracterizando programas de investigação ou linhas de pesquisa, conforme os interesses dos que realizam tais atividades, pode haver diferentes tipos de intervenção profissional sobre essas complexas interações - raramente em uma única direção de influência -, realizadas com os mais variados recursos ou procedimentos, conforme a variável, ou conjunto, escolhido como "alvo" da intervenção, e pelos múltiplos tipos de profissionais que podem interferir nos diferentes tipos e graus dessas relações entre condições de saúde e condições psicológicas dos organismos, incluindo as variáveis que interferem com as interações entre essas duas condições e nas interações das variáveis que constituem cada uma dessas condições. Os limites e possibilidades de estudo e de intervenção nessas relações não são nem claros nem suficientemente conhecidos. $E$ talvez o mais importante sejam exatamente essas possibilidades que o desconhecido ainda contém e a forma de explorá-las no estudo, na intervenção e no ensino para a formação de psicólogos. Os conceitos de área de conhecimento e de campo de atuação profissional, em contraste com a de "mercado de trabalho" examinadas por Botomé (1988), Rebelatto (1994) e Rebelatto e col. (1999), reforçam ainda mais essas possibilidades de entendimento na abrangência do que fica sob o nome "saúde" e, nesse sentido, também sob o nome "Psicologia em saúde".

Mais do que considerar "Psicologia em Saúde" uma "área" com técnicas, conceitos e problemas já configurados, a formação de novos profissionais pode enfatizar os instrumentos básicos de análise e intervenção sobre variáveis que constituem e se relacionam com fenômenos psicológicos. Com isso, provavelmente, estarão aptos a identificar e intervir sobre variáveis que, sendo psicológicas, interferem sobre a saúde - biológica, social ou psicológica ou que, sendo do âmbito da saúde - ambientais, econômicas, fisiológicas, biológicas, físicas, políticas, administrativas etc. -, interferem sobre as condições psicológicas de organismos, individual ou coletivamente. De qualquer forma, mais do que "fechar sua fronteiras" no que foi feito e é conhecido, a "Psicologia em Saúde" parece ser um campo de atuação (possibilidades de atuação) em grande parte ainda inexplorado e desconhecido pelos serviços de Psicologia e pelo ensino que deveria capacitar para a realização de um serviço que, efetivamente, atendesse às necessidades da sociedade.

Não parece mais ser suficiente o trabalho dos profissionais de saúde - psicólogos ou outros - ficar restrito a atenuar sofrimento, compensar dano, corrigir lesões, recuperar prejuízos 
e minimizar a atuação nos âmbitos da prevenção de problemas (psicológicos e de saúde), no qual é necessária uma atuação antes que os problemas aconteçam e de uma maneira para que não venham a ocorrer (Stédile, 1996; Rebelatto e col. 1999). Formar um profissional capacitado a atuar nesses diferentes níveis já é exigência muito grande de estudos e de intervenções sistêmicas. Mas, ainda é necessário capacitar os novos psicólogos a trabalharem também com manutenção de boas condições de saúde e de comportamentos significativos na sociedade e com promoção de melhores condições nos dois casos. Conhecer as variáveis que viabilizam tais tipos de atuações e ensinar formas de realizar intervenções desse tipo é um desafio importante e urgente para os que investigam a área de conhecimento chamada Psicologia e para os que capacitam profissionais a intervir nos problemas sociais, inclusive os denominados de "problemas de saúde", seja no âmbito que for e apesar das limitações que as convenções administrativas, burocráticas, políticas ou das simples práticas imponham e forcem o pensamento e os comportamentos de quem, com sua atuação, pode ampliar as possibilidades de atuação das novas gerações de psicólogos.

Em síntese, as linhas de trabalho e os programas de estudo que se reúnem sob o nome de "Psicologia da Saúde" não definem nem os limites nem as possibilidades de estudo e de intervenção da Psicologia em relação à Saúde. E a compreensão desses limites e possibilidades pode ser uma importante condição para o futuro da pesquisa, do ensino e da atuação dos que se reúnem - bem ou mal - sob o rótulo "Psicologia da Saúde". Dizer que "Psicologia em Saúde" pode ser uma expressão melhor que "Psicologia da Saúde" pode indicar uma disposição e um significado que se referem a fenômenos de maior amplitude, maior complexidade, com mais interfaces e interações com fenômenos reunidos sob outros nomes que não os usualmente adotados ou reconhecidos como "psicologia" ou como "saúde". A Epidemiologia Social, os estudos de Saúde Pública e os avanços do conhecimento sobre os fenômenos e processos psicológicos feitos nas últimas décadas do século $X X$, possibilitam uma nova e melhor compreensão do que pode ser reunido sob o nome de Psicologia em Saúde e as vantagens que isso traz para o desenvolvimento do conhecimento e da intervenção em relação a esses fenômenos e processos tanto quanto para o ensino das competências importantes para constituir a formação de profissionais para trabalhar com eles.

\section{REFERÊNCIAS BIBLIOGRÁFICAS}

Angerami, V. A. (1997). O psicólogo no hospital. Em V. A. Angerami-Camon (Org.) Psicologia hospitalar: teoria e prática. São Paulo: Livraria Pioneira Editora.

Arcaro, N. T. \& Mejias, N. P. (1990). A evolução da assistência psicológica e em saúde mental: do individual para o comunitário. Psicologia: Teoria e Pesquisa, 6(3), 251-266.

Bandeira, M. (1992). Desinstitucionalização: estão os profissionais de Psicologia preparados? Psicologia: Teoria e Pesquisa, 8(3), 373-384.

Bastos, A. V. B. (1988). Áreas de atuação - em questão o nosso modelo de profissão. Em Conselho Federal de Psicologia (Org.), Quem é o psicólogo brasileiro? (p. 163-193). São Paulo: Edicon Editora e Consultoria.

Bastos, A. V. B. \& Achcar, R. (1994). Dinâmica profissional e formação do psicólogo: uma perspectiva de integração. Em Psicólogo brasileiro: práticas emergentes e desafios para a formação (p. 245-271). São Paulo: Casa do Psicólogo.

Botomé, S. P. (1981A). Administração de comportamento humano em instituições de saúde: uma experiência para serviço público. Dissertação de mestrado apresentada ao Programa de Pós Graduação em Psicologia Experimental da Universidade de São Paulo. São Paulo.

Botomé, S. P. (1981B). Objetivos comportamentais no ensino: a contribuição da Análise Experimental do Comportamento. Tese de doutorado apresentada ao Programa de Pós Graduação em Psicologia Experimental da Universidade de São Paulo.

Botomé, S. P. \& Santos, E. V. (1984). Ensino na área de saúde: o problema do objeto de trabalho. Ciência e Cultura, 36(6), 910-923.

Botomé, S. P. (1988). Em busca de perspectivas para a Psicologia como área de conhecimento e como campo profissional. Em Conselho Federal de Psicologia (org.) Quem é o psicólogo brasileiro? (p. 273-297). São Paulo: Edicon Editora e Consultoria.

Botomé, S. P. (1998). Análise do comportamento em educação: algumas perspectivas para o desenvolvimento de aprendizagens complexas. Texto elaborado para o concurso de professor titular para o Departamento de Psicologia da Universidade Federal de Santa Catarina.

Carvalho, A. M. A. (1982). A profissão em perspectiva. Psicologia, 8(2), 5-18.

Chaves, M. M. (1980). Saúde e sistemas. Rio de Janeiro: Editora da Fundação Getúlio Vargas.

Conselho Federal de Psicologia (Org.) (1988). Quem é o psicólogo brasileiro? São Paulo: Edicon Editora e Consultoria.

Conselho Federal de Psicologia (Org.) (1992). Psicólogo brasileiro: construção de novos espaços. Campinas: Editora Átomo. 
Conselho Federal de Psicologia (Org.) (1994). Psicólogo brasileiro: práticas emergentes e desafios para a formação. São Paulo: Casa do Psicólogo.

Ferreira, M. R. \& Botomé, S. P. (1984). Deficiência física e inserção social - a formação dos recursos humanos. Caxias do Sul: Editora da Universidade de Caxias do Sul.

Huertas, F. (1996). O método PES (Planejamento Estratégico Situacional): entrevista com Matus. São Paulo: Edições FUNDAP.

Lobianco, A. C.; Bastos, A. V. B.; Nunes, M. L. T. \& Silva, R. C.da (1994). Concepções e atividades emergentes na psicologia clínica: implicações para a formação. Em R. Achcar (Coord. geral), Psicólogo brasileiro: práticas emergente e desafios para a formação (p. 7-79). São Paulo: Casa do Psicólogo.

Melchiori, L. E. (1987). Derivação de comportamentos institucionais e profissionais em relação a pessoas com "deficiência mental" a partir da caracterização da incidência desse problema na população de um município. Dissertação de mestrado apresentada ao Programa de Pós-graduação em Educação Especial da Universidade Federal de São Carlos. São Carlos (SP).

Mello, S. L. (1975). Psicologia e profissão em São Paulo. São Paulo (SP): Editora Ática.

Nóbrega, C. (1996). Em busca da empresa quântica: analogias entre o mundo da ciência e o mundo dos negócios. Rio de Janeiro: Ediouro.

Nóbrega, C. (1998). A Ciência e os negócios. Exame, 31(7), 76-91.

Rebelatto, J. R. (1994). Área de conhecimento e campo de atuação profissional: uma distinção fundamental para gerenciar a qualidade do trabalho universitário. Revista IGLU, 7, 97-113.

Rebelatto, J. R. e Botomé, S. P. (1999). Fisioterapia no Brasil: perspectivas de evolução como campo profissional e como área de conhecimento. São Paulo: Editora Manole.

Rouquayrol, M. Z. (1994). Epidemiologia e saúde (4ª ed.). Rio de Janeiro: Editora Médica e Científica.

Silva, R. C. (1992). A formação em Psicologia para o trabalho na saúde pública. Em F. C. B. Campos (Org.), Psicologia e saúde: repensando práticas (p. 25-40). São Paulo: Editora Hucitec.

Skinner, B. F. (1938). The behavior of organisms. New York: Appleton-Century-Crofts.

Skinner, B. F. (1969). Contingencies of reinforcement: a theoretical analysis. New York: Appleton-CenturyCrofts.

Spink, M. J. P. (1992). Psicologia da saúde: a estruturação de um novo campo de saber. Em F. C. B. Campos (Org.), Psicologia e saúde: repensando práticas (p. 11-23). São Paulo: Editora Hucitec.

Stédile, N. L. R. (1996). Prevenção em saúde: comportamentos profissionais a desenvolver na formação do enfermeiro. Dissertação de mestrado apresentada ao Programa de Pós-Graduação em Educação - Área Metodologia do Ensino, da Universidade Federal de São Carlos. São Carlos.

Todorov, J. C. (1989). Psicologia como estudo de interações. Psicologia: Teoria e Pesquisa, 5(3), 347-356.

Zannon, C. M. L. C. (1991). Desenvolvimento psicológico da criança: questões básicas relevantes à intervenção comportamental no ambiente hospitalar. Psicologia: Teoria e Pesquisa, 7(2), 119-136. 